\title{
Qualitative
}

\section{Resilience was not necessarily a healthy concept for adolescents in inner city vocational high schools}

Hunter AJ, Chandler GE. Adolescent resilience. Image:Journal of Nursing Scholarship 1999 Third Quarter;31:243-7.

QUESTION: What does resilience mean to adolescents?

Design

Triangulated research design.

\section{Setting}

Inner city vocational high schools in a New England state, USA.

\section{Participants}

51 students in the $10^{\text {th }}$ and $11^{\text {th }}$ grade ( $55 \%$ girls) participated. Students were identified as high risk, low income minority adolescents with a high rate for dropping out, gang membership, teen pregnancy, and violence.

\section{Methods}

The qualitative component of the study consisted of a free writing exercise patterned after the Schneider (1993) WRITE method whereby individuals get in touch with their feelings and thoughts by writing in response to a stimulus. The intent was to provide stimuli that would allow adolescents to tell their stories about surviving and overcoming adversities in their lives. The adolescents participated in the 50 minute writing and focus group discussion exercises in their English classes. The adolescents wrote for 10 minutes in response to a stimulus for each of 9 days. After writing, the adolescents and facilitators read their stories and expressed their thoughts and feelings. The discussion and activities in these focus group sessions were recorded by a participant observer and all facilitators maintained a daily journal to record their perceptions of the experience.

\section{Main results}

The adolescents' perceptions of their resilience was based on their sense of invincibility, insulation of feelings, isolation of self from those who could hurt them, distrust of everyone around them, acting out, and being violent to be heard and seen. Resilience to them meant being insular, disconnected, self reliant, self protective with no one to depend on or trust but themselves. Resiliency Scale scores indicated that the adolescents in this study perceived themselves as resilient. The results of the qualitative component of this study suggested, however, that resilience meant something very different to these adolescents than what the Resiliency Scale purported to measure. Being resilient was not having a healthy sense of self, a strong sense of self worth, or the ability to connect and trust others. Being resilient meant surviving.

\section{Conclusion}

Resilience in adolescents in inner city vocational high schools was a process of defense using tactics such as insulation, isolation, disconnecting, denial, and aggression or was a process of survival using responses such as violence.

\section{COMMENTARY}

All practitioners working with adolescents should be encouraged to read this elegant pilot study, not necessarily because of the primary topic of inquiry (resilience) but because of some of the incidental features of the study.

As Hunter and Chandler outline in their introduction, "resilience" is often viewed as a healthy and positive state. In contrast, "vulnerability" is viewed as an unhealthy state that requires intervention.

According to the Resiliency Scale used in this study (a valid and reliable tool developed by Wagnild and Young 1993), the adolescents were, indeed, resilient. Further exploration of their resilience using qualitative methods, however, revealed a contradiction: although resilient, the adolescents were also vulnerable.

The discovery that resilience and vulnerability can co-exist is not in itself problematic: Hunter and Chandler posit a model of resilience that succinctly shows how these concepts can co-exist. The warning that should go out to practitioners, however, is not to assume that resilient adolescents are less in need of intervention than are vulnerable adolescents.

An incidental feature of the study was the observation that aspects of the research process (the creative writing aspect in particular) appeared to aid in the development of healthy resilience. This finding might have alarmed a pure researcher but the authors judiciously balance the needs of research and practice when discussing it and rightly contend that it is a finding worthy of further research.

A second incidental feature of the study relates to its triangulated design. The key finding of the study-that resilience and vulnerability are not necessarily independent constructs-emerged as a result of this design. Given the value of this finding, practitioners would be well advised to consider triangulation in practice, particularly where assessment is concerned. In other words, a more accurate picture of an individual's situation and needs is more likely to be forthcoming if both qualitative and quantitative data are taken into account.

Steven Pryjmachuk, RMN, MSc University of Manchester Manchester, UK
A J Hunter, Clems

8646565488 . 